\title{
Fimosis y Circuncisión
}

\author{
FELIPE CASTRO S. ${ }^{1}$, FELIPE CASTRO A. ${ }^{2}$, TRINIDAD RABY B. ${ }^{2}$ \\ 1. Cirujano Pediatra Servicio de Cirugía Pediátrica Hospital Sótero del Río. \\ 2. Interno Facultad de Medicina Universidad de Los Andes.
}

\begin{abstract}
Phimosis and Circumcision

The term phimosis is used when the prepuce cannot be reytracted behind the glans. This condition is oresent in almost all newborns, fulfilling mostly a protective function. In childhood, a gradual separation occurs, which is completed in adolescence. Through this process, complications may happen such as urinary tract infections, balanitis, or paraphimosis. Circumcision has been considered the treatment of choice, although some factors must be weighed: degree of narrowing, complications, opinión and religious beliefs of the parents. In the past 15 years, publications have suggested topical steroids as an alternative treatment, with variable success. Treatment of phimosis will continue to be controversial.
\end{abstract}

(Key words: Phimosis, circumcision, prepuce, glans).

Rev Chil Pediatr 2010; 81 (2): 160-165

\section{RESUMEN}

El término fimosis se utiliza cuando el prepucio no puede ser retraído por detrás del glande. Esta condición está presente en casi todos los recién nacidos cumpliendo una función principalmente protectora. Durante la infancia se produce una separación gradual del prepucio, que se completa, en la mayoría de los casos, al llegar la adolescencia. Mientras ocurre el proceso de desprendimiento pueden presentarse complicaciones como; infección del tracto urinario, balanitis o parafimosis. La circuncisión ha sido tradicionalmente el tratamiento de elección, sin embargo, se debe tener en cuenta diversos factores antes de tomar una decisión quirúrgica. Debe ser considerado: el grado de estrechez, las complicaciones, la opinión y las creencias religiosas de los padres. En los últimos 15 años se han publicado numerosos trabajos sobre el uso de esteroides tópicos como alternativa terapéutica, con resultados de éxito variable. El tratamiento de la fimosis seguirá siendo un tema controvertido.

(Palabras clave: Fimosis, prepucio, glande, circuncisión).

Rev Chil Pediatr 2010; 81 (2): 160-165

Trabajo recibido el 07 de octubre de 2009, aceptado para publicación el 23 de diciembre de 2009.

Correspondencia a:

Felipe Castro Aguirre.

E-mail: figo_05@hotmail.com 


\section{Introducción}

El prepucio es la porción de piel que cubre el cuerpo peneano y el glande. Cumple variadas funciones incluyendo la de protección, erógena e inmunológica. Al momento de nacer se encuentra firmemente adherido al glande por su cara mucosa, por lo que es imposible retraer en la mayoría de los casos. Esta adherencia es una condición fisiológica y a medida que transcurre el tiempo se va desprendiendo espontáneamente siendo infrecuente en la adolescencia. Durante este proceso pueden presentarse complicaciones atribuibles a esta condición, y se deben tomar conductas terapéuticas precisas para su tratamiento. Hasta el día de hoy persisten las diferencias sobre la conducta a seguir tanto en un recién nacido, como en los casos que presentan complicaciones y especialmente en lo que se refiere a la circuncisión como solución definitiva. A esto se agrega un ambiente cultural y religioso que ejerce una gran influencia en la toma de decisiones.

El objetivo de esta revisión es: 1) describir las características y funciones propias del prepucio en la edad pediátrica; 2) analizar la evolución y complicaciones de la fimosis en los niños; 3) proponer una conducta terapéutica coherente con las evidencias actualmente disponibles.

\section{Fimosis fisiológica}

La fimosis se define como la incapacidad para retraer completamente el prepucio detrás del glande, no atribuible a adherencias balanoprepuciales (figura 1). Como esta condición se presenta en la mayoría de los recién nacidos se ha denominado fimosis fisiológica a diferencia de la patológica, que se presenta principalmente entre los 8 y los 11 años debido a un proceso cicatricial del prepucio distal secundario a una balanitis xerótica obliterante. A medida que transcurre el tiempo el prepucio se va desprendiendo espontáneamente, al año de edad el desplazamiento prepucial bajo el glande es posible en un $64 \%$, lo que aumenta al $81 \%$ a los 11 años. La incidencia de fimosis a los 8 años es del $8 \%$ y a los 16 alcanza un $1 \%{ }^{1}$.
Mientras se completa el proceso, puede ser causa predisponente de otras patologías tales como infección urinaria, balanitis y parafimosis.

\section{Fimosis patológica}

\section{Balanitis xerótica obliterante (líquen escleroatrófico)}

Es una afección crónica del prepucio distal de etiología desconocida. En la mayoría de los casos afecta sólo el glande y el prepucio, pero en ocasiones también puede extenderse hacia el meato y la uretra anterior (figura 2). $\mathrm{Su}$ mayor incidencia es entre los 8 y los 11 años. Clínicamente se manifiesta por esclerosis anular distal del prepucio con decoloración blanquecina o formación de placas, estrechez prepucial, irritación, disuria y en ocasiones sangrado. El tratamiento depende de la gravedad de las lesiones y de los elementos comprometidos. Si el daño se limita al prepucio y el compromiso es leve, se puede intentar un tratamiento inicial usando corticoides tópicos, si esto fracasa estaría indicada la circuncisión. Si hay lesión del meato o la uretra se realiza una meatotomía o injerto uretral ${ }^{2}$.

\section{Diagnóstico diferencial}

\section{Estrechez, anular}

Ocurre en aquellos casos en que es posible desplazar el prepucio hacia proximal por debajo del glande evidenciándose un anillo estrecho (figura 3). Si esta condición se prolonga por algunas horas y no se desplaza hacia distal se producirá una parafimosis. En los casos de estrechez anular se debe instruir a la madre o al niño sobre el cuidado que hay que tener o proponer una prepucioplastía cuando el desplazamiento prepucial sea dificultoso o asociado a dolor.

\section{Adherencias balanoprepuciales}

A medida que el prepucio se va desprendiendo del glande producto de erecciones intermitentes y de la queratinización del epitelio interno, se evidencian las adherencias balanoprepuciales (figura 4). Estas impiden una 


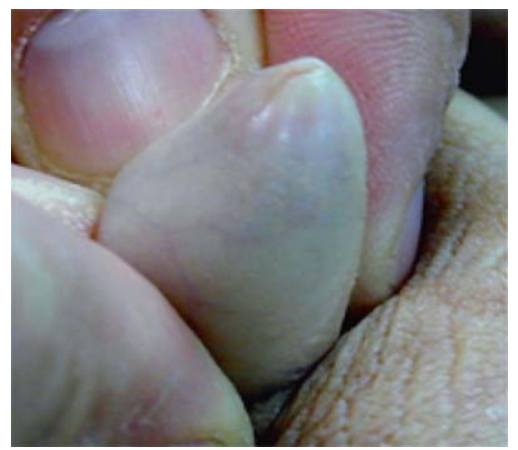

Figura 1. Fimosis fisiológica.

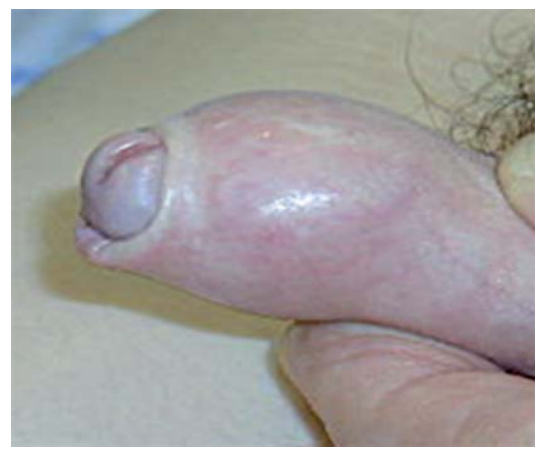

Figura 2. Balanitis xerótica obliterante.

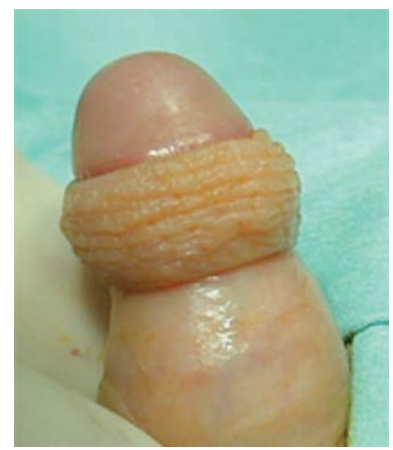

Figura 3. Estrechez anular del prepucio.

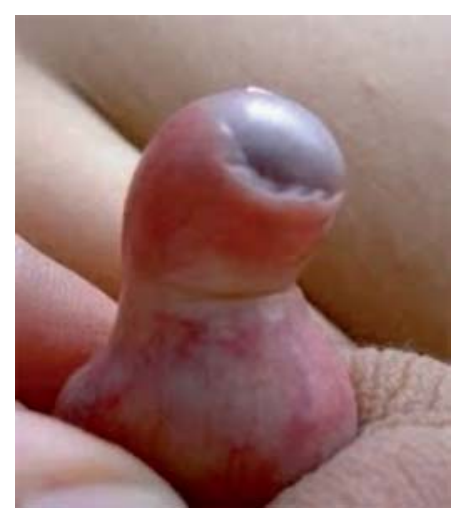

Figura 4. Adherencias balanoprepuciales.

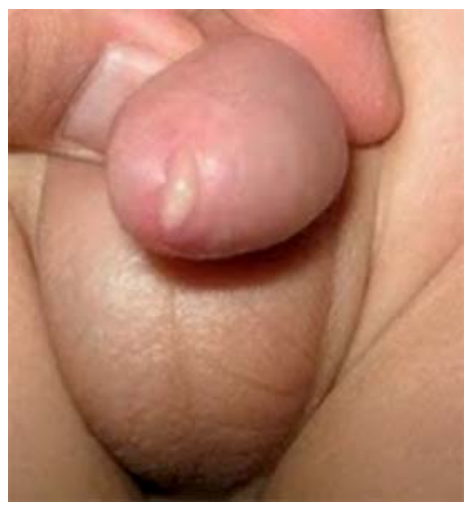

Figura 5. Balanitis.

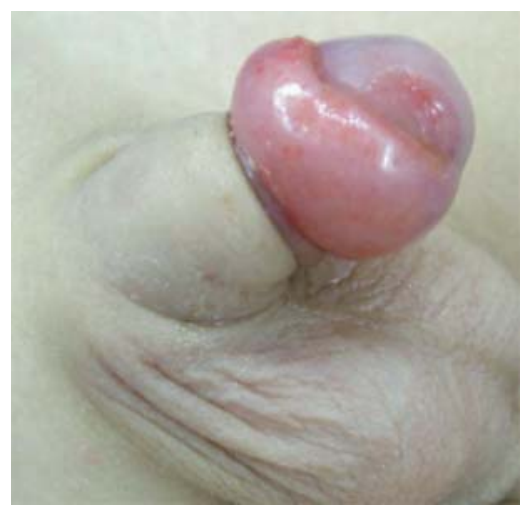

Figura 6. Parafimosis. retracción total del prepucio pero no debido a una estrechez real. Ya que es una condición fisiológica transitoria, la mayoría de las veces exenta de complicaciones, no requiere de un tratamiento específico. En ocasiones, se puede producir un desprendimiento brusco provocando dolor localizado, en esta situación, es conveniente indicar una pomada protectora local mientras se logra la epitelización del glande.

\section{Complicaciones}

\section{Balanitis}

Es una infección del espacio balanoprepucial, debido principalmente a una higiene deficiente de la zona (figura 5). Los gérmenes causantes más frecuentes son la E. Coli y el Proteus Vulgaris, aunque en el $30 \%$ el cultivo es negativo. Se presenta principalmente entre los 2 y los 4 años, cuando aún existe un prepucio total o parcialmente adherido. Se puede diagnosticar por la presencia de eritema y edema del prepucio con salida de secreción purulenta. El tratamiento consiste en el lavado prolijo del espacio balanoprepucial con suero fisiológico durante 2 a 3 días, además de analgésicos y antiinflamatorios que ayudan a aliviar la sintomatología. El uso de antibióticos está reservado exclusivamente para aquellas ocasiones en las cuales exista compromiso de tejidos vecinos. La circuncisión estaría indicada en los casos de balanitis recurrente ${ }^{4}$.

\section{Parafimosis}

Es una inflamación aguda del prepucio debido a una reducción forzada de una estrechez anular, que al quedar en posición proximal al glande provoca una obstrucción de la circulación produciendo edema y dolor intenso (figura 6). En la mayoría de los casos y dependiendo 
de las horas de evolución, se puede tratar mediante una maniobra manual que consiste en aplicar una presión constante sobre el glande con los pulgares, lo que permite el desplazamiento del prepucio hacia distal. Si no se logra reducir, se debe realizar una circuncisión o una prepucioplastía bajo anestesia general.

\section{Infección urinaria y fimosis}

Uno de los temas más controversiales es la relación que existe entre infección urinaria (ITU) y estrechez prepucial. En un estudio retrospectivo donde se evaluaron lactantes menores de 1 año con ITU febril y sin malformación urinaria asociada, se encontró que era más frecuente en el sexo masculino con una relación 4 a 1 . En el $80 \%$ de los niños el prepucio no era retráctil y en el $84 \%$ de ellos la ITU recidivó antes de 6 meses. La recurrencia fue de un $21 \%$ en un plazo de un año, significativamente mayor en los niños menores de 6 meses $(26 \%$ vs $7,7 \%$.) y en los que el prepucio permaneció estrecho después de la primera infección $(34 \% \text { vs } 18 \%)^{5}$. En un metanálisis sobre prevalencia de ITU en la infancia, se encontró que en los circuncidados menores de 3 meses fue de un 2,4\% y en los no circuncidados llegó al 20,7\%. La prevalencia de ITU en los circuncidados entre los 6 y los 12 meses fue de un $0,3 \%$, mientras que en los no circuncidados fue de un 7,3\%. No se encontró información en los mayores de 1 año ${ }^{6}$. Estos estudios demuestran que la estrechez prepucial es un factor determinante en la ITU de los lactantes, por lo tanto, se debería instruir a las madres para mantener un buen aseo de la zona y proponer un tratamiento definitivo para evitar la recurrencia de ITU, especialmente en los menores de 1 año. Sing-Grewal y col, en una revisión sistemática, concluyeron que se necesitaban realizar 111 circuncisiones para evitar una ITU, 11 para evitar una ITU recurrente y 4 para evitar una ITU en niños con reflujo vesicoureteral (RVU) con grados igual o mayor a III $^{7}$.

\section{Enfermedades de transmisión sexual y circuncisión}

Otro de los aspectos sobre el cual existe abundante literatura es la relación entre enfer- medades de transmisión sexual y circuncisión. El VIH (virus de inmuno deficiencia humana) se contrae, en el caso del hombre, durante el acto sexual por la penetración del virus a través de la mucosa prepucial. Los factores que favorecen esta infección son una alta concentración de células blanco para VIH y una capa de queratinización muy delgada de la mucosa, lo que la hace muy susceptible a presentar lesiones traumáticas ${ }^{8}$. Estudios randomizados controlados hechos en países africanos han demostrado que la circuncisión ha disminuido en un $58-60 \%$ el riesgo de contraer la enfermedad y que es ésta la estrategia que tiene la mejor relación costo beneficio 9 . También se ha demostrado un efecto beneficioso sobre otras enfermedades de transmisión sexual como la infección por virus papiloma, virus herpex simple tipo 2 y sífilis ${ }^{10,11}$.

\section{Malformación de las vías urinarias y circuncisión}

La mayoría de los urólogos pediátricos han adoptado empíricamente la conducta de realizar una circuncisión en pacientes con ITU que tienen asociada una malformación del tracto urinario como valvas uretrales, RVU, vejiga neurogénicas y otras. No existen en la literatura muchos trabajos publicados al respecto. Mukherjee y col, en un estudio de un grupo de pacientes con valvas uretrales encontraron que la circuncisión redujo la incidencia de ITU en un $83 \%$, mientras que las derivaciones urinarias realizadas no tuvieron ningún efecto $^{12}$. Por otro lado, Thiruchelvam y Cuckow revisaron el efecto de la circuncisión en 18 pacientes, 13 con valvas uretrales ( 8 de ellos con RVU) y 5 con RVU grados IV y V. Después de la operación, 12 de los 18 niños no tuvieron ITU recurrente y 2 tuvieron una sóla recurrencia. Cuatro pacientes fueron intervenidos quirúrgicamente (reimplante ureteral) terminando con una insuficiencia renal crónica (IRC). La circuncisión en esta serie fue menos efectiva en los niños con IRC, lo que se pudo deber a que las infecciones recurrentes contribuyeron al efecto inmunosupresor de la IRC y a la reducción del flujo urinario ${ }^{13}$. De acuerdo con estos datos, la circuncisión se debería realizar precozmente en todos los pacientes con 
una uropatía severa para evitar la falla renal crónica. Por otro lado, en un estudio ramdomizado Kwak y col, demostraron que no había diferencias significativas en la incidencia de ITU después de una cirugía antirreflujo en los pacientes que se realizaba la circuncisión simultáneamente en comparación con los no circuncidados $^{14}$.

\section{Tratamiento}

Existen básicamente dos métodos para el tratamiento de los pacientes con estrechez prepucial que presenta una complicación o un alto riesgo de contraer una enfermedad favorecida por esta condición: 1) la circuncisión y 2) la aplicación de masajes con pomadas de corticoides.

La circuncisión es el procedimiento quirúrgico más frecuente realizado en niños. Su origen se remonta a 15000 años atrás, motivado por razones religiosas, culturales y médicas. Se estima que el $10 \%$ de la población mundial es circuncidada, variando significativamente sus porcentajes según la zona geográfica.

Las indicaciones médicas actuales se clasifican en absolutas y relativas. La balanitis xerótica obliterante, y la balanitis recurrente son indicaciones absolutas. Entre las relativas se encuentran las que se asocian a ITU en menores de 1 año, ITU recurrente, uropatías obstructivas de las vías urinarias y como prevención de cáncer de pene, cérvico-uterino y enfermedades de transmisión sexual, particularmente el VIH. La operación se realiza bajo anestesia general, su duración es de aproximadamente media hora y el paciente es dado de alta el mismo día. Las complicaciones ocurren en menos del $2 \%$ y las más frecuentes son el sangrado, infección localizada, estenosis del meato, resultados cosméticos deficientes y recidiva. Hay que considerar que está contraindicada en algunas hipospadias y en los pacientes que presentan pene sumido, ya que agrava esta condición. La decisión de una circuncisión especialmente cuando existe una causa relativa debe ser tomada en conjunto con los padres, considerando la información actual, los beneficios y el riesgo de complicaciones.
En cuanto a los corticoides locales, existen numerosos trabajos publicados sobre la aplicación de estos en la zona prepucial para obtener un desplazamiento adecuado del prepucio. Se han obtenido diversos resultados según las distintas series, dependiendo principalmente del grado de estrechez inicial y de la adherencia al tratamiento. El éxito reportado es de un 60- $90 \%$ con una recurrencia de un $20 \%{ }^{15,16}$. Está indicado como primera opción en lactantes que presentan estrechez e ITU. También como una alternativa en los pacientes cuyos padres rechazan el tratamiento quirúrgico, en estos casos se debe advertir la posibilidad de un fracaso o recidiva. Se han usado diferentes preparados con corticoides siendo uno de los más usados en nuestro medio la crema de betametasona al 1\% durante un período de 4 a 8 semanas. No se recomienda usarlas en niños que no presentan patologías asociadas, ya que en la gran mayoría el desprendimiento prepucial ocurre espontáneamente.

\section{Referencias}

1.- Morales JC, González P, Morales A, Guerra A, Mora $B$ : Fimosis. Necesidad de circuncisión o dilatación del prepucio. Estudio de 1.200 niños. Arch Esp Urol 2008; 61 (6): 699-704.

2.- Gargollo PC, Kozakewich HP, Bauer SB, et al: Balanitis xerotica obliterans in boys. J Urol 2005; 174 (4 Pt 1): 1409-12.

3.- Pileggi Fde O, Vicente YA: Phimotic ring topical corticoid cream $(0.1 \%$ mometasone furoate $)$ treatment in children. J Pediatr Surg 2007; 42 (10): 1749-52.

4.- Rickwood AM: Medical indications for circumcision. BJU Int 1999; 83 Suppl 1: 45-51.

5.- Shim YH, Lee JW, Lee S: The risk factors of recurrent urinary tract infection in infants with normal urinary systems. J Pediatr Nephrol 2009; 24 (2): 309-12.

6.- Shaikh N, Morone NE, Bost JE, Farrell MH: Prevalence of urinary tract infection in childhood: a meta-analysis. Pediatr Infect Dis J 2008; 27 (4): 302-8

7.- Singh-Grewal D, Macdessi J, Craig J: Circumcision for the prevention of urinary tract infection in boys: a systematic review of randomised trials and observational studies.Arch Dis Child 2005; 90 (8): 853-8.

8.- Morris BJ: Why circumcision is a biomedical imperative for the 21(st) century. Bioessays 2007; 29 (11): 1147-58. 
9.- Auvert B, Marseille E, Korenromp EL, et al: Estimating the resources needed and savings anticipated from rollout of adult male circumcision in Sub-Saharan Africa. PLoS ONE 2008; 3 (8): e2679.

10.- Giuliano AR, Lazcano E, Villa LL, et al: Circumcision and sexual behavior: factors independently associated with human papillomavirus detection among men in the HIM study. Int J Cancer 2009 15; 124 (6): 1251-7.

11.- Tobian AA, Charvat B, Ssempijja V, et al: Factors Associated with the Prevalence and Incidence of Herpes Simplex Virus Type 2 Infection among Men in Rakai, Uganda. AIDS 2009; 23 (12): 1589-94.

12.- Mukherjee S, Joshi A, Carroll D, Chandran H, Parashar $K$, McCarthy $L$ : What is the effect of circumcision on risk of urinary tract infection in boys with posterior urethral valves? J Pediatr Surg 2009; 44 (2): 417-21.

13. Thiruchelvam N, Cuckow PM: Effect of circumcision on urinary tract infection after successful antireflux surgery. BJU Int 2005; 95 (3): 453-4.

14.- Kwak C, Oh SJ, Lee A, Choi H: Effect of circumcision on urinary tract infection after successful antireflux surgery. BJU Int 2004; 94 (4): 627-9.

15.- Zavras N, Christianakis E: Conservative treatment of phimosis with fluticasone propionate $0.05 \%$ : a clinical study in 1185 boys. J Pediatr Urol 2009; 5 (3): 181-5.

16.- Esposito C, Centonze A: Topical steroid application versus circumcision in pediatric patients with phimosis: a prospective randomized placebo controlled clinical trial. World J Urol 2008; 26 (2): 187-90. 